The Bangladesh Veterinarian (2010) 27(2) : $74-81$

\title{
Fertility and parasitic infestation of Red Chittagong cattle
}

\author{
S. Das, A. K. F. H. Bhuiyan", N. Begum¹, M. A. Habib and T. Arefin \\ Department of Animal Breeding and Genetics, Faculty of Animal Husbandry, Bangladesh \\ Agricultural University, Mymensingh-2202, Bangladesh
}

\begin{abstract}
Fertility of Red Chittagong bulls (RCB) using Non-Return Rate (NRR), reproductive efficiency of Red Chittagong cows (RCC) using pregnancy rate and number of services per pregnancy and parasitic infestation of two different ages and sexes were studied. The NRR ranged from $53.1 \%$ to $70.6 \%$ with an overall mean of $63.9 \%$. Overall pregnancy rate was $65.8 \%$ and about 1.4 services were required per pregnancy. Overall $47.7 \%$ animals were infested with parasites. Five species of parasites were detected in the faeces: Balantidium coli (40\%), Paramphistomum spp (47.7\%), Fasciola spp (5.8\%), Coccidia spp (4.5\%), and Moniezia spp (1.9\%). The prevalence of parasites in animals over four years age was higher $(\mathrm{P}<0.05)$ than in animals below four years of age: the prevalence was higher in female than in male hosts ( $\mathrm{P}>0.05)$. (Bangl. vet. 2010. Vol. 27, No. 2, $74-81$ )
\end{abstract}

\section{Introduction}

The profit of a dairy farm depends on the production of calves and milk. Calving interval, age at puberty, services per pregnancy and interval to onset of post-partum heat are considered important parameters to measure farm economy (Azizunnesa, 2002). Low production of dairy cows may be due to their poor genetic make-up, inadequate feeding and disease control and harsh environments (Jabber and Green, 1998; Shamsuddin, 1988). The cattle of Bangladesh are mostly non-descript indigenous type and among these Red Chittagong cows (RCC) is an important resource, having characteristics of small size, regular breeding, and good adaptability in hot humid climate (Habib et al., 2003).

In order to evaluate the fertilizing capacity of bull spermatozoa, at least 525 cows are to be inseminated and after 60 days non-return rate (NRR) of the bulls can be calculated (Willett and Salisbury, 1942). Payne (1970) suggested that (NRR) is a useful method of expressing fertility of bulls in Artificial Insemination (AI) programmes. The climatic conditions in Bangladesh favour parasites. To improve productivity of Red Chittagong Cattle (RCC), it is necessary to investigate the parasitic infestation and fertility.

\footnotetext{
1 Department of Parasitology, Faculty of Veterinary Science, Bangladesh Agricultural University, Mymensingh 2202, Bangladesh

* Corresponding author. E-mail: bhuiyanbau@gmail.com
} 


\section{Materials and Methods}

Individual records of animals of RCC nucleus herd and AI centre of the Bangladesh Agricultural University were used. The reproductive performance of 52 RCC and six RCB was collected from the record books. Results of faecal samples examination of RCC nucleus herd were used to identity parasitic infestation. NRR, pregnancy rate, services per pregnancy and parasitic infestation were studied using standard procedures. Fertility of bulls was measured as the percentage of cows that did not return to oestrus by 60 days after AI. Cow's fertility was measured from the number of cows found pregnant divided by total number of animals served. Pregnancy was confirmed by rectal examination at 60 days after AI. The following formulae were used :

(1) Non return rate of bull $(\%)=\frac{\text { Cows not returned to oestrus within } 60 \text { days }}{\text { Total number of cows inseminated by the bull }} \times 100$

(2) Pregnancy rate $(\%)=\frac{\text { Number of animals found pregnant }}{\text { Total number of animals served }} \times 100$

Faecal samples of all RCC animals were collected at six-month intervals. About $10-20 \mathrm{~g}$ fresh faecal samples were directly collected by inserting the hand in to the animal's rectum: samples were put into polythene bags with $10 \%$ formalin solution and refrigerated until examination. The quantitative estimation of faecal eggs or cysts of Balantidium coli, ova of Paramphistomum and other parasites were done by employing 'Modified Stoll's Dilution Technique' as described by Soulsby (1982). In brief, three grams of well-mixed faecal sample were put into a $100 \mathrm{ml}$ beaker containing $42 \mathrm{ml}$ of water, some glass beads were added to it. Then it was thoroughly mixed with a stirrer. The mixture was then strained with a coffee strainer, shaken well and $0.15 \mathrm{ml}$ was taken using one $\mathrm{ml}$ special pipette and put on glass slide and covered with cover slip. Care was taken to avoid bubble formation. The slide was then examined under microscope and eggs were identified on the basis of morphological features and counted. The counts were made from each sample and the total number of eggs of parasites found in the slide was multiplied by 100 to get the eggs per gram of faeces (EPG).

\section{Statistical analysis}

The data generated were entered into Microsoft Excel Worksheet. Descriptive statistics were performed to calculate mean, standard error of mean and percentage. One-way Analysis of Variance (ANOVA) was done. All statistical analysis was performed using SPSS (Statistical Package for Social Sciences) in Windows package. 


\section{Results and Discussion}

Non-Return Rate (NRR \%) of Bulls

The 60-day NRR rate of different RCB were estimated between $53.1 \pm 11.6$ to 70.6 $\pm 11.4 \%$ with an overall mean of $63.9 \%$. Almquist et al. (1954) reported NRR for high fertility bulls from 65 to $74 \%$ and for low fertility bulls 52 to $65 \%$. Schaeffer (1993) reported the value of this trait ranging from 52.1 to $75.7 \%$ for exotic dairy breeds of different ages. Our results were slightly lower than those of Almquist et al. (1954); Schaeffer (1993). Williamson et al. (1978) reported NRR to first insemination from 58.2 to $69.3 \%$ for dairy herds in Victoria. Fryer et al. (1958) reported the value of this trait ranging from 44 to $71 \%$ in different ages of reputed exotic dairy breeds. Our results were within the range of Williamson et al. (1978); Fryer et al. (1958). The variation among different authors might be due to small sample and poor management. Non-return rate was largely dependent on the management, number of services, age and environment.

\section{Pregnancy rate}

The average pregnancy rate of RCC was $65.8 \pm 4.5 \%(\mathrm{n}=94)$. Gaur et al. (2002) found pregnancy rate $54 \%$ for cows and $46 \%$ for heifers in Ongole cattle in India, which was lower than this study. The pregnancy rate depends on genetic and nongenetic factors including the cow herself, semen quality, time of insemination, proper heat detection efficiency on skill-ness of inseminator. Das et al. (1990); Rodriguez and Hernandez (1992) found significant variations in pregnancy rate when cows were inseminated at different times after the first sign of heat. The pregnancy rate of cows markedly reduced when a higher ambient temperature prevailed for two days before insemination to 4-6 days after insemination (Gwazdauskas et al., 1975). Higher environmental temperature and relative humidity and poor management affected fertility of cattle (Zakari et al., 1981).

\section{Number of services per pregnancy}

The mean number of services per pregnancy in RCC was $1.4 \pm 0.06(n=94)$, which was lower than other crossbred cows: these results agree with the findings of Islam and Bhuiyan (1997); Singh et al. (1997). The latter reported services per pregnancy of $1.2( \pm 0.2)$ in Jersey cross cows $(J R), 1.4( \pm 0.2)$ in JR $\times$ SN (Sindhi) and $1.5( \pm 0.1)$ in PM (Pabna Milch) $\times$ SL (Sahiwal), $1.2( \pm 0.1)$ in $1 / 4 \mathrm{PM} \times$ SL cows at Baghabarighat milk-shed area of Bangladesh. Sultatna (1995) showed the number of services per pregnancy of Local, Local $\times$ Jersey $\left(\mathrm{F}_{1}\right)$, and Local $\times$ Friesian was 1.8, 2.0 and 1.7, respectively. Nutritional status of cattle, management, poor heat detection and efficiency of inseminator play a vital role for this trait. Shiferaw et al. (2003) found that cows with reproductive disorders required more services for pregnancy. Proper and accurate heat detection is a key to efficient reproduction and four to five checks each day to determine the sign of standing heat gives a better idea when to inseminate. 


\section{Parasitic infestation}

A total of 155 faecal samples from cattle of different ages and both sexes were examined from August 2006 to September 2008. The overall prevalence of parasitic infestation was $47.7 \%$.

A total of five different parasites were detected (Table 1): Balantidium coli $(40 \%)$, Paramphistomum (47.7\%), Fasciola (5.8\%), Coccidia (4.5\%) and Moniezia spp. (2.0\%). The overall mean EPG was maximum for Balantidium coli (267.7) followed by Paramphistomum (127.7), Moniezia (50.0) and Fasciola (47.2). The overall mean Oocyst per gram (OPG) for Coccidia was 96.4. Sardar et al. (2006) reported maximum prevalence for Paramphistomum (45.3\%) followed by Fasciola $(25 \%)$ and Moniezia (8.3\%) for native cattle in Mymensingh, which partially agrees with this study. According to the report of Garrel (1975), 83.7\% cattle were suffering from parasitic infestation in Bangladesh. In India, Bhattacharyya and Ahmed (2005) and Singh et al. (2008) recorded the incidence of gastrointestinal helminths of $65.2 \%$ and $80.0 \%$, respectively. In Japan, Nakazawa (1986) found 79\% cattle with gastrointestinal helminths. The variation in prevalence of parasites among different workers could be due to environment, feeding, management, and genetic variation in host resistance.

Table 1. Prevalence of parasitic load in Red Chittagong cattle

\begin{tabular}{l|c|c|c}
\hline \multicolumn{1}{c|}{ Name of parasite } & $\mathrm{N}$ & Prevalence $(\%) \mathrm{n}=155$ & $\begin{array}{c}\text { Egg per gram of facees } \\
\text { (Mean } \pm \text { SE) }\end{array}$ \\
\hline Balantidium coli & 62 & 40.0 & $267.7 \pm 38.7$ \\
Paramphistomum spp & 74 & 47.7 & $127.7 \pm 10.5$ \\
Fasciola spp & 9 & 5.8 & $47.2 \pm 13.5$ \\
Coccidia spp & 7 & 4.5 & $96.4 \pm 14.9$ \\
Moniezia spp & 3 & 2.0 & $50.0 \pm 0.0$ \\
\hline
\end{tabular}

Age had a significant effect $(\mathrm{P}<0.05)$ on the prevalence of parasites: young animals were more susceptible than adult except Fasciola and Coccidia.

In animals under four years $42.6 \%$ were infested with parasites (Table 2). Prevalence of Paramphistomum (51.5\%) and B. coli (40.9\%) were highest followed by Fasciola and Coccidia (both 3\%) and Moniezia (1.5\%). The highest parasitic infestation was found for Coccidia (113) followed by Paramphistomum (70), B. coli (60), Moniezia (50) and Fasciola (38). In adult cattle (>4 years) $57.4 \%$ were infested. The highest rate of infestation was Paramphistomum (45.0\%) followed by B. coli (40\%), Fasciola (8\%), Coccidia $(6 \%)$ and Moniezia (1\%). The highest parasitic infestation in that age was found for B. coli (355) followed by Paramphistomum (177), Coccidia (90), Fasciola and Moniezia (both 50). Age had significant $(\mathrm{P}<0.01)$ effect on the prevalence of $B$. coli and Fasciola. Prevalence of Paramphistomum varied significantly $(\mathrm{P}<0.01)$ in both young 
and adult animals. The animals below four years of age had a higher prevalence of Paramphistomum, B. coli and Moniezia and for a lower prevalence of Fasciola and Coccidia than did animals of more than four years. Sardar et al. (2006) recorded higher prevalence of Fasciola and lower prevalence of Moniezia with age, which coincides with this study, but differs with regard to Paramphistomum. Adult livestock had higher overall prevalence than young cattle (Ibrahim et al., 2008), which was consistence with the present findings.

Table 2. Prevalence of different parasites according to age

\begin{tabular}{c|c|l|c|c}
\hline Age & No. & \multicolumn{1}{c|}{ Parasite } & Prevalence $(\%) \mathrm{n}=155$ & $\begin{array}{c}\text { Egg per gram of facees } \\
\text { (Mean } \pm \text { SE) }\end{array}$ \\
\hline$<4$ Years & 66 & Paramphistomum spp & $34(51.5 \%)$ & $69.9 \pm 10.3$ \\
& & B. coli & $27(40.9 \%)$ & $59.7 \pm 8.6$ \\
& & Fasciola spp & $2(3.0 \%)$ & $37.5 \pm 12.5$ \\
& & Coccidia spp & $2(3.0 \%)$ & $112.5 \pm 12.5$ \\
& & Moniezia spp & $1(1.5 \%)$ & $50.0 \pm 0.0$ \\
\hline$>4$ years & Total & Paramphistomum spp & $66(42.6 \%)$ & \\
& B. coli & $30(44.9 \%)$ & $176.9 \pm 13.1$ \\
& Fasciola spp & $7(40.4 \%)$ & $354.9 \pm 59.6$ \\
& Coccidia spp & $5(5.6 \%)$ & $50.0 \pm 17.3$ \\
& Moniezia spp & $1(1.1 \%)$ & $90.0 \pm 20.3$ \\
& Total & $89(57.4 \%)$ & $50.0 \pm 0.0$ \\
\hline
\end{tabular}

$\mathrm{n}=$ Number of positive specimens

Sex of the host had no significant effect on prevalence of helminths but females had higher prevalence of Paramphistomum and Coccidia than males. On the other hand males had higher prevalence of Fasciola and Monieziea than females (Table 3). Prevalence of parasites was higher in female $(82.6 \%)$ than male $(17.4 \%)$. The rate of infestation in female was highest in case of Paramphistomum (50\%) followed by B. coli $(40 \%)$, Coccidia (5.5\%), Fasciola (4\%) and Monieziea (1\%). The higher parasitic load in female was for B. coli (301) followed by Paramphistomum (141), Coccidia (96), Fasciola (55) and Monieziea (50). In males, the prevalence was highest in case of B. coli (41\%) followed by Paramphistomum (37\%), Fasciola (15\%), Monieziea (7\%) and Coccidia (0\%). The highest mean parasitic load in male was B. coli (116) followed by Paramphistomum and Monieziea (both 50) and Fasciola (38). Raza et al. (2007) and Islam and Taimur (2008) observed higher rates of nematode infection in female hosts than in males. Prevalence of infestation was higher in females $(82.7 \%)$ than in males $(53.4 \%$; Singh et 
al., 2008). Their results were in agreement with this finding. In contrast, Ibrahim et al. (2008) reported higher prevalence of parasitic infestation in male than female hosts. Higher prevalence of parasites in females compared with males might be due to lower resistance of female during pregnancy.

It could be concluded that reproductive efficiency of RCC was reasonable when compared to published reports in other breeds. The prevalence of parasitic infestation was lower than in other breeds. Thus, steps should be taken to control those parasites.

Table 3. Prevalence of parasites according to sex

\begin{tabular}{l|c|l|c|c}
\hline Age & No. & Name of parasites & Prevalence (\%) & $\begin{array}{c}\text { Egg per gram of facees } \\
\text { (Mean } \pm \text { SE) }\end{array}$ \\
\hline Female & 128 & Paramphistomum spp & $64(50.0 \%)$ & $140.6 \pm 11.3$ \\
& & B. coli & $51(39.8 \%)$ & $300.5 \pm 12.7$ \\
& & Coccidia spp & $7(5.5 \%)$ & $96.4 \pm 14.9$ \\
& Fasciola spp & $5(3.9 \%)$ & $55.0 \pm 11.2$ \\
& Monieziea spp & $1(0.8 \%)$ & $50.0 \pm 0.0$ \\
\hline Male & Overall & Paramphistomum spp & $128(82.6 \%)$ & \\
& B. coli & $11(37.0 \%)$ & $50.0 \pm 8.3$ \\
& Coccidia spp & - & $115.9 \pm 17.3$ \\
& Fasciola spp & $4(14.8 \%)$ & - \\
& Moniezia spp & $2(7.4 \%)$ & $57.5 \pm 7.2$ \\
& Overall & $27(17.4 \%)$ & $50.0 \pm 0.0$ \\
\hline
\end{tabular}

\section{References}

Almquist JO, Flipse RJ, Thacker DL 1954: Diluters of bovine semen, IV: Fertility of bovine spermatozoa in heated homogenized milk and skim milk. Journal of Dairy Science 37 1303-1307.

Azizunnesa BC 2002: Economic opportunity survey of the subsistence dairy farm in Mymensingh district. MS Thesis, Department of Surgery and Obstetrics, Faculty of Veterinary Science, Bangladesh Agricultural University, Mymensingh, Bangladesh.

Bhattacharyya DK, Ahmed K 2005: Prevalence of helmintic infection in cattle and buffaloes. Indian Veterinary Journal 82 900-901.

Das SC, Ahmed JU, Alam MGS 1990: Conception rate in Zebu cows using frozen Sahiwal semen. Bangladesh Veterinary Journal 24-26 90-93. 
Fryer, HC, Marion GB, Farmer EL 1958: Nonreturn rate of artificially inseminated dairy cows as affected by age of semen, breed of bull, and season. Journal of Dairy Science 41 987-993.

Garrel G 1975: Gastro-intestinal parasitic infection of cattle in some village of Dhaka and Tangail district in Bangladesh. Bangladesh Veterinary Journal 9 9-10.

Gaur, G.K, Kaushik SN, Garg RC 2002: Ongole cattle status in India. Animal Genetic Resources Information 32 27-34.

Gwazdauskas FC, Wilcox CJ, Thatcher WW 1975: Environmental and managemental factors affecting conception rate in a subtropical climate. Journal of Dairy Science 58 88-92.

Habib MA, Bhuiyan AKFH, Bhuiyan MSA, Khan AA 2003: Performance of Red Chittagong Cattle in Bangladesh Agricultural University Dairy Farm. Bangladesh Journal of Animal Science 32 101-108.

Ibrahim MM, Ghamdi MAA, Gahmdi MSA 2008: Helminths Community of Veterinary Importance of Livestock in Relation to Some Ecological and Biological Factors. Turkey Journal of Parasitology 32 42-47.

Islam KBMS, Taimur MJFA 2008: Helminthic and protozoan internal parasitic infections in free ranging small ruminants of Bangladesh. Slovenian Veterinary Research 45 67-72.

Islam, SS, Bhuiyan, AKFH 1997: Performance of crossbred Sahiwal at the Pabna milk shed area in Bangladesh. Asian-Australasian Journal of Animal Science 10 581-586.

Jabber MA, Green DAG 1998: The status and potential of livestock within the context of agricultural development policy in Bangladesh. Department of Agricultural Economics., Aberystwyth. Adran Economy Amaethydol, University of Walea, United Kingdom pp. 37-57.

Nakazawa M 1986: Parasitological survey and the anthelmintic effect of ivermectin on the gastro-intestinal nematodes in cattle of Hokkaido, Japan. Japanese Journal of Veterinary Research 34143.

Payne WJA 1970: Cattle Production in the Tropics. Vol. 1. Longman Group Ltd. London, United Kingdom pp. 336.

Raza MA, Iqbal Z, Jabbar A, Yaseen M 2007: Point prevalence of gastrointestinal helminthiasis in ruminants in Southern Punjab, Pakistan. Journal of Helminthology 81 323-328.

Rodriguez HT, Hernandez C 1992: Effect of time of insemination and rectal temperature on fertility in cows. Animal Breeding Abstract 60288.

Sardar SA, Ehsan MA, Anower AKMM, Rahman MM, Islam MA 2006: Incidence of liverflukes and gastro-intestinal parasites in cattle. Bangladesh Journal of Veterinary Medicine 4 39-42.

Schaeffer LR 1993: Evaluation of Bulls for Nonreturn Rates within Artificial Insemination Organizations. Journal of Dairy Science 76 837-842.

Shamsuddin M 1988: Factors affecting conception rates in cattle. MSc Thesis, Department of Surgery and Obstetrics, Faculty of Veterinary Science, Bangladesh Agricultural University, Mymensingh, Bangladesh. 
Shiferaw Y, Tenhagen BA, Bekana M, Kassa T 2003: Reproductive performance of crossbred dairy cows in different production systems in the central highlands of Ethiopia. Tropical Animal Health and Production 35 551-561.

Singh NP, Deb SM, Mehrotra S 1997: Performance of Holstein cattle in temperate hills in India. Indian Journal of Dairy Science 50 7-11.

Singh A, Gangwar AK, Shinde NK, Srivastava S 2008: Gastrointestinal parasitism in bovines of Faizabad. Journal of Veterinary Parasitology 22(1), vide: http://www. indianjournals.com/ijor.asp $x$ ?target $=$ ijor:jvp\&volume $=22 \&$ issue $=1 \&$ article $=008$

Soulsby EJL 1982: Helminths, Arthropods and protozoa of domesticated animals, $7^{\text {th }}$ edition, Bailliere Tindall, London, United Kingdom, pp. 764-766.

Sultana R 1995: Quantitative analysis of reproductive performance of purebred and their crosses in the Savar Dairy farm. MSc Thesis, Department of Animal Breeding and Genetics, Faculty of Animal Husbandry, Bangladesh agricultural University, Mymensingh, Bangladesh.

Willett EL, Salisbury GW 1942: The effect of various diluters, cooling rate, temperature of storage and some other factors on the liveability of spermatozoa in stored samples of bull semen. Cornell University Agricultural Experimental Station, USA, Memoir, pp. 249.

Williamson, NB, Morris RS, Anderson GA 1978: Pregnancy rates and non-return rates following artificial and natural breeding in dairy herds. Australian Veterinary Journal 54 111-114.

Zakari AY, Molokwu ECL, Osori DIK 1981: Effect of rectal and ambient temperature and humidity on conception rate. Theriogenology 16 331-336. 